\title{
STATUS OF ANTIOXIDANT DEFENCE SYSTEM FOR DETOXIFICATION OF ARSENIC IN BRASSICA JUNCEA (L.)
}

\author{
Mohd. Kafeel Ahmad Ansari ${ }^{1,2,4^{*}}$, Munir Hussain $\mathrm{Zia}^{6}$, Altaf Ahmad', \\ Ibrahim Mohammed Aref ${ }^{5}$, Tasneem Fatma ${ }^{1}$, Muhammad Iqbal ${ }^{2}$ and Gary Owens $^{4}$ \\ ${ }^{1}$ Cyanobactrial Biotechnology Laboratory, Department of Biosciences, Faculty of Natural Sciences \\ Jamia Millia Islamia (A Central University), New Delhi, 110025, India. \\ ${ }^{2}$ Molecular Ecology Laboratory, Department of Botany, Faculty of Science, Hamdard University \\ Hamdard Nagar, New Delhi, 110062, India \\ ${ }^{3}$ Nanobiotechnology Laboratory, Department of Botany, Faculty of Life Sciences \\ Aligarh Muslim University, Aligarh, India \\ ${ }^{4}$ Environmental Contaminants Group, Mawson Institute, University of South Australia \\ Mawson Lakes, SA 5095, Australia \\ ${ }^{5}$ Department of Plant Production, College of Food and Agricultural Sciences \\ King Saud University, Riyadh 11451, Saudi Arabia \\ ${ }^{6}$ Environmental Chemistry Laboratory, British Geological Survey, Keyworth, United Kingdom \\ *Email: kafeelansari123@gmail.com
}

\begin{abstract}
The content of arsenic (As), a naturally occurring toxic element found in soils worldwide, has gone substantially high in agricultural soils due to various anthropogenic activities. The responses of seed germination, seedling growth, photosynthetic pigments and the components of the ascorbateglutathione (AsA-GSH) pathway were analyzed in Indian mustard [Brassica juncea (L.) Czern.] cultivar Pusa Jai Kisan, treated with 0, 5, 10, 25 and $50 \mu \mathrm{M}$ As concentrations in a hydroponic system. While a significant increment in lipid peroxidation and $\mathrm{H}_{2} \mathrm{O}_{2}$ generation was observed at higher concentrations after 2 and 5 days of stress imposition. Significant increases were also observed in superoxide dismutase (SOD), catalase (CAT), ascorbate peroxidase (APX), and glutathione reductase (GR) activities under the influence of 25 and $50 \mu \mathrm{M}$ As concentrations after 2 and $5 \mathrm{~d}$ stress impositions. There was a steep increase in the ascorbic acid (AsA) content between 2 and $5 \mathrm{~d}$ after As treatment, while glutathione (GSH) content increased significantly after 5-d-exposure. Accumulation of As was more in shoot than in root. This study clearly demonstrated that high concentration $(50 \mu \mathrm{M})$ of As inhibited growth and caused oxidative stress and the AsA-GSH pathway has an important role in cellular defense against As in Brassica juncea (L.).
\end{abstract}

Key words: Antioxidative enzymes, AsA-GSH pathway, chloroplast pigments, oxidative stress, seed germination. 


\section{INTRODUCTION}

Contamination of groundwater and soil by arsenic (As), a trace metalloid, is a worldwide problem and poses a potential risks to humans and the environment. As-enriched water is a major source of contamination of the food chain and water supplies (Khan et al. 2009).

Efficient, sustainable and environment-friendly ways for removal of As from polluted sites are needed to preserve the quality of drinking water, agricultural products as well as environment. Chaney (1983) was the first to propose the idea of phytoremediation as a 'green' environmentfriendly strategy for remediating the metalcontaminated soil and water, in which plants absorb, accumulate and detoxify contaminants from the substrates where they grow through physical, chemical or biological processes (Iqbal et al. 2014). The main attribute necessary for metal hyperaccumulation in plants is metalhypertolerance, which results from an interconnected ensemble of physiological and molecular mechanisms (Diwan et al. 2008). Phytoremediation relies mainly on hyperaccumulators, which possess immense ability of heavy-metal accumulation. A model plant for metal cleaning should be rapid in growth, easy in harvesting and capable to tolerate and accumulate large metal concentrations in its shoot (Iqbal et al. 2014). Indian mustard [Brassica juncea (L.) Czern.], which compensates for its comparatively less metal accumulation by its large yield of shoot dry matter, is recognized with the ability to extract and store metals like $\mathrm{Cd}, \mathrm{Cu}, \mathrm{Ni}, \mathrm{Zn}, \mathrm{Pb}$ and $\mathrm{Se}$ into its shoots (Ansari et al. 2015).

A strong antioxidant-defense system is another characteristic that imparts heavy-metal tolerance to plants (Suthar et al. 2014). The oxidative stress in plants primarily occurs due to heavy metal-induced generation of free radicals, including toxic reactive oxygen species (ROS) (Ansari et al. 2009).
However, in order to cope with these ROS-caused anomalies plants have efficient antioxidant defense system that comprises of enzymatic [like superoxide dismutase (SOD), catalase (CAT), glutathione reductase (GR) ] as well as nonenzymatic [like glutathione (GSH), ascorbate (AsA), carotenoids] components (Khan et al. 2009). SOD is the enzyme that catalyzes the dismutation of $\mathrm{O}_{2}^{-}$to $\mathrm{H}_{2} \mathrm{O}_{2}$. The enzymes and metabolites of the AsA-GSH cycle are responsible for the regulation of the $\mathrm{H}_{2} \mathrm{O}_{2}$ level (Khan et al. 2009). The equilibrium between the SOD activity and the activities AsA-GSH cycle enzymes could be critical in deciding the steady-state concentration of $\mathrm{O}_{2}{ }^{-}$and $\mathrm{H}_{2} \mathrm{O}_{2}$. This equilibrium, in addition to the metal-ion sequestration, is thought to be vital for the prevention of ROS formation via the Haber-Weiss or Fenton reactions (Anjum et al. 2014).

Despite several works on As-induced changes in plants, information is still deficient on modulation of the AsA-GSH-cycle and changes in growth and physiological attributes of plants under As stress. The main objective of this study was to examine whether the growth characteristics are altered and the antioxidant enzymes are modulated in cultivar Pusa Jai Kisan of Indian mustard, when grown under As stress in hydroponic conditions; if yes, whether this can act as a potential As accumulator.

\section{MATERIALS AND METHODS}

Plant growth conditions: Indian mustard (Brassica juncea L. Czern. cv. Pusa Jai Kisan) seeds were procured from the Indian Agricultural Research Institute, New Delhi, India, and germinated on Whatman filter paper soaked in distilled water and kept in the dark for 3 days in a controlled growth chamber at the temperature of $25^{\circ} \mathrm{C}$. After germination, these seedlings were shifted to plastic beakers having $250 \mathrm{~mL}$ nutrient solution 
comprised of $3 \mathrm{mM} \mathrm{KNO} \mathrm{KN}_{3}, 2 \mathrm{mM} \mathrm{Ca}\left(\mathrm{NO}_{3}\right)_{2}, 1$ $\mathrm{mM} \mathrm{NH}{ }_{4} \mathrm{H}_{2} \mathrm{PO}_{4}, 50 \mu \mathrm{M} \mathrm{KCl}, 25 \mu \mathrm{M} \mathrm{H}_{3} \mathrm{BO}_{3}, 2 \mu \mathrm{M}$ $\mathrm{MnCl}_{2}, 2 \mu \mathrm{M} \mathrm{ZnCl} 2,0.5 \mu \mathrm{M} \mathrm{CuCl}{ }_{2}, 0.5 \mu \mathrm{M}\left(\mathrm{NH}_{4}\right)$

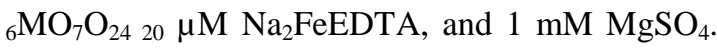
The $\mathrm{pH}$ of the solution was maintained at $6.5 \pm 0.1$ with $0.1 \mathrm{M} \mathrm{NaOH}$. This nutrient solution was aerated continuously with an aeration pump to increase the oxygen level and replaced weekly. The beakers were arranged in a randomized block design and replicated four times. Each beaker had ten plants. After 10 days of growth, plants were treated with $0,5,10,25$ and $50 \mu \mathrm{M}$ of As in the form of $\mathrm{Na}_{3} \mathrm{AsO}_{4}$. A photosynthetic photon-flux density (PPFD) of $200 \mu \mathrm{mol} \mathrm{m} \mathrm{m}^{-2}$ was given to the seedlings by combining fluorescent tubes with tungsten lamps, maintaining a photoperiod of $16 \mathrm{~h}$. The plants harvested at 2 and $5 \mathrm{~d}$ after As-stress imposition, were rinsed properly with distilled water prior to analysis and measurements. The plant material was separated into roots and shoots (stem + leaves).

Seed germination and arsenic toxicity: Seed germination was tested on wet Whatman (No. 42 $\mathrm{mm}$ ) filter paper placed in Petri dishes. The paper in Petri dish was moistened with $3.0 \mathrm{~mL}$ solution of different As treatments. In the control, the filter paper was moistened with $3.0 \mathrm{~mL}$ distilled water. Twenty seeds were placed in each petri dish, which were kept in a growth chamber at $25^{\circ} \mathrm{C}$ in the dark for 3 days. Each treatment was replicated three times. Germinated seeds were counted on 2 and 5 days after initiation of treatment. The seeds were considered germinated when both plumule and radicle were extended from their junction.

Growth parameters and chloroplast pigments: After obtaining the fresh mass, the plants were dried at $70^{\circ} \mathrm{C}$ in an oven for determining their dry mass. The root and shoot lengths were measured with a standard scale. The net photosynthetic rate $\left(\mathrm{P}_{\mathrm{N}}\right)$ of the leaves was calculated with the infrared gas analyzer (IRGA, LI-6400, Lincoln, NE, USA) from the fully expanded uppermost leaves of plants at the maximum irradiance between 11:00-12:00

h. Chlorophyll content of the leaves was estimated by the method of Hiscox and Israelstam (1979).

Assays of antioxidant enzymes: Fresh leaves (0.5 g) were homogenized in a chilled mortar and pestle, using an extraction buffer having $100 \mathrm{mM}$ potassium phosphate $(\mathrm{pH} 7.0), 0.5 \%$ (v:v) Triton $\mathrm{X}-100$ and $1 \%(\mathrm{w}: \mathrm{v})$ polyvinylpyrrolidone (PVP). The centrifugation of this homogenate was done at $15,000 \times \mathrm{g}$ at a temperature of $4^{\circ} \mathrm{C}$ for $20 \mathrm{~min}$ and the enzymes were assayed using the resultant supernatant.

The SOD activity was estimated with the method described by Dhindsa et al. (1981) by recording the hinderance of photochemical reduction of nitro-blue tetrazolium (NBT). The enzyme quantity needed for $50 \%$ inhibition of the photochemical reduction of NBT was considered as one unit of SOD activity. CAT activity was estimated according to Aebi (1984) by recording the $\mathrm{H}_{2} \mathrm{O}_{2}$ disappearance and calculated using the extinction coefficient of $0.036 \mathrm{mM}^{-1} \mathrm{~cm}^{-1}$. One unit of enzyme referred to quantity of enzyme required for decomposition of $1 \mu \mathrm{mol}$ of $\mathrm{H}_{2} \mathrm{O}_{2}$ per min at $25^{\circ} \mathrm{C}$. To assay the activity of ascorbate peroxidase (APX), the extraction buffer was supplemented with $2 \mathrm{mM}$ ascorbate. APX activity was estimated by the method of Nakano and Asada (1984) and measured using an extinction coefficient of 2.8 $\mathrm{mM}^{-1} \mathrm{~cm}^{-1}$. One unit of enzyme was the amount required for decomposition of $1 \mu \mathrm{mol}$ of the substrate per min at $25^{\circ} \mathrm{C}$. GR activity was estimated by the method of Foyer and Halliwell (1976) by recording the oxidation of NADPH and using an extinction coefficient of $6.2 \mathrm{mM}^{-1} \mathrm{~cm}^{-1}$. One unit of the enzyme refers to the quantity needed for decomposition of $1 \mu \mathrm{mol}$ of NADPH per min at $25^{\circ} \mathrm{C}$. Protein content was estimated by the procedure of Bradford (1976), taking the bovine serum albumin (BSA) as a protein standard. The activity of the enzymes was expressed in terms of enzyme units (EU) $\mathrm{mg}^{-1}$ protein. 
Statistical analysis: The values shown in this work are a mean of four independent observations. A two-way ANOVA test was used for the confirmation of data significance. The comparison with the control and treatments was performed using the Duncan's multiple range tests (DMRT). Changes in antioxidative enzyme activities with As concentration were fit to an exponential rise to the maximum of the form $\mathrm{A}_{\mathrm{C}}=\mathrm{A}_{0}+\Delta \mathrm{A}\left(1-\mathrm{e}^{-\mathrm{bC}}\right)$, where $C$ was the As concentration in $\mu \mathrm{M}$ and $A_{C}$ was enzyme activity at concentration $\mathrm{C}$ in $\mathrm{EU} \mathrm{mg}^{-1}$ protein $\min ^{-1}, \mathrm{~A}_{0}$ was the initial enzyme activity without stress at $0 \mu \mathrm{M}$ As, $\Delta \mathrm{A}$ was the maximum increase in enzyme activity equivalent to $A_{\max }-A_{0}$ and $b$ was a fitting parameter determining the shape of the incline. The best-fit parameters were determined using the least squares (Sigma Plot, USA).

Estimation of non-enzymatic antioxidants: Fresh plant tissue (1g) was ground with sand $(0.2 \mathrm{~g})$ in $6.5 \%$ m-phosphoric acid ( $5 \mathrm{~mL}$ ) with $1 \mathrm{mM}$ EDTA, using a mortar and pestle. The AsA content was estimated by the method of Hodges et al. (1996), and calculated as nmol g $\mathrm{g}^{-1}$ fresh mass (FM). GSH contents were determined by the method of enzymatic GSSG recycling (Bergmeyer et al. 1974). The reaction was monitored spectrophotometrically by stoichiometric conversion of NADPH done at the baseline of NADPH absorbance $(340 \mathrm{~nm})$. Standard calibration curve was obtained by using $100 \mathrm{~mL}$ of GSSG instead of the sample. One unit $\mathrm{mL}^{-1} \mathrm{GR}$ was taken to calculate the total glutathione (GSH+GSSG) and GSSG, respectively. The GSH content was obtained by subtracting the GSSG content from the total glutathione and expressed in $\mu \mathrm{mol} \mathrm{g}{ }^{-1} \mathrm{FM}$.

Oxidative stress traits: The content of thiobarbuteric acid (TBA) reactive substances, including malondialdehyde (MDA), which are considered to be the products of lipid-peroxidation, were determined in plant samples by the slightly modified method of Heath and Packer (1968). The freshly obtained plant tissue $(1 \mathrm{~g})$ was ground in 10 $\mathrm{mL}$ of $0.1 \%$ TCA (trichloroacetic acid), followed by centrifugation at $10286 \times \mathrm{g}$ for $5 \mathrm{~min}$. The supernatant $(1 \mathrm{~mL})$ was then combined with $0.5 \%$ TBA in $20 \%$ TCA $(4 \mathrm{~mL})$ in a test tube and subjected to a temperature of $95^{\circ} \mathrm{C}$ for $30 \mathrm{~min}$, followed by quick cooling in an ice bath and the centrifugation at $2571 \times \mathrm{g}$ for $5 \mathrm{~min}$. The absorbance of the supernatant at $532 \mathrm{~nm}$ was corrected for unspecific turbidity by subtracting the absorbance at $600 \mathrm{~nm}$. The concentration of lipid peroxidation was expressed as $\mu$ mol MDA formed $\mathrm{g}^{-1} \mathrm{FW}$ using an extinction coefficient of $155 \mathrm{mM}$ $\mathrm{cm}^{-1}$.

The $\mathrm{H}_{2} \mathrm{O}_{2}$ concentration was estimated calorimetrically, as described by Okuda et al. (1991). $\mathrm{H}_{2} \mathrm{O}_{2}$ was extracted by homogenizing plant tissue $(0.5 \mathrm{~g})$ with $200 \mathrm{mM}$ perchloric acid (4 mL). The homogenate was subjected to centrifugation of $12,000 \times \mathrm{g}$ for $10 \mathrm{~min} . \mathrm{H}_{2} \mathrm{O}_{2}$-induced oxidation of ferrous ions to ferric ions in acidic $\mathrm{pH}$ was monitored and the stable complex of ferric ions with xylenol orange dye was measured at $560 \mathrm{~nm}$. The $\mathrm{H}_{2} \mathrm{O}_{2}$ content was shown in $\mathrm{nmol} \mathrm{g} \mathrm{g}^{-1} \mathrm{FW}$.

Elemental analysis: The As contents in roots and shoots were calculated after the samples were subjected to digestion in sulphuric/nitric acid mixture $(2: 1, \mathrm{v} / \mathrm{v})$. The harvested plant material was washed thoroughly with Milli-Q water (resistivity $>18 \mathrm{M} \Omega \mathrm{cm}$ at $25^{\circ} \mathrm{C}$ ), dried at $65^{\circ} \mathrm{C} \pm$ $2^{\circ} \mathrm{C}$ for $72 \mathrm{~h}$, and digested after grinding to fine powder, using the method of Ansari et al. (2015). In brief, dry material $(0.25 \mathrm{~g})$ from each treatment sample was added to concentrated $\mathrm{HNO}_{3}(3 \mathrm{~mL})$ in a $50 \mathrm{ml}$ digestion tube and swirled gently for mixing. These digestion tubes were kept for $1 \mathrm{~h}$ at $150^{\circ} \mathrm{C}$ in a heating block set. Subsequently, the tubes were cooled. Afterwards, $2 \mathrm{~mL}$ of $30 \% \mathrm{H}_{2} \mathrm{O}_{2}$ 
was put in each digestion tube and heated for an additional $3 \mathrm{~h}$ at $150^{\circ} \mathrm{C}$. Finally, the tubes were cooled down to room temperature. After the plant tissues were completely digested, the solution was diluted to $50 \mathrm{~mL}$ and the supernatant analyzed for of As content, using an atomic absorption spectrophotometer (ZEEnit 65, Analytik Jena, Germany) fitted with a graphite tube of the Wall type (Ansari et al. 2015).

\section{RESULTS AND DISCUSSION}

Seed germination: Data obtained on seed germination indicated that As was highly toxic to the genotype studied. Seed-germination rate declined significantly with increase in As concentration applied. The reduction in seed germination, which varied day wise, was in the range of $8-40 \%$ on the $2^{\text {nd }}$ day and $12-60 \%$ on the $5^{\text {th }}$ day of experiment, as compared with the control (Fig. 1). Thus, the reduction was highest and most significant on the $5^{\text {th }}$ day. Our results indicate that seed germination was minimized significantly with increase As treatments, as recorded on the $2^{\text {nd }}$ and the $5^{\text {th }}$ day of treatment. Similar effects of As on seed germination have been observed in wheat, rice, and green gram (Mumthas et al. 2010). Seed germination relies almost solely on seed reserves of metabolites available for meeting the requirement of respiration other anabolic reactions. The starch is quantitatively the most copious storage material in the seeds, and the available evidence suggests that in germinating seeds starch is degraded predominantly via the amylolytic pathway (Mumthas et al. 2010). Seed coat provides protection from metal stress prior to germination, but it cracks finally crack or becomes more permeable upon germination. It is known that seed germination is affected by metals or metalloid due to their toxicity that causes various nutritional disturbances and also suppression of water uptake.

Thus, metal treatment normally causes a concentration-dependent diminution in seed germination, as observed in a number of species (Lamhamdi et al. 2011).

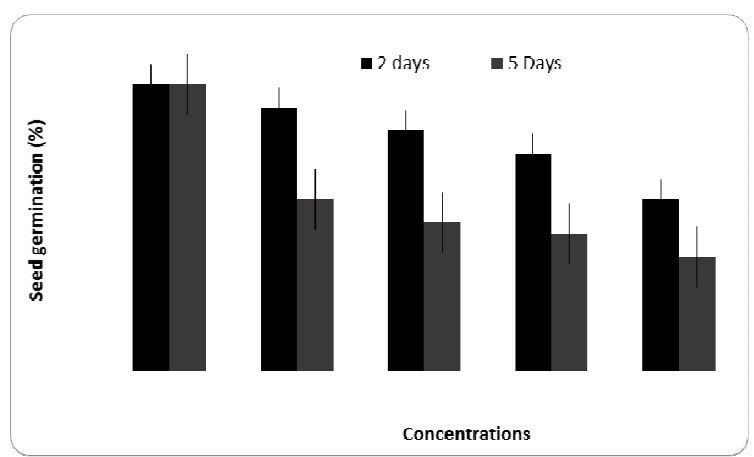

Fig. 1. Seed germination percentage of $2 \& 5$ day old Brassica juncea cv. Pusa Jai Kisan grown with and without As stress. All values are the mean of four independent experiments with four replications each $(n=12)$. Significant $(p$ $\leq \mathbf{0 . 0 5})$ compared to control. The percentage error in replicate reproducibility was $<2 \%$ in all cases.

Growth variables: The mild dose of As $(5 \mu \mathrm{M})$ did not affect the biomass, root and shoot lengths, photosynthesis and chlorophyll content in the species studied. However, a gradual decrease in these parameters was observed with increasing As concentration in the medium (Table 1). Relative to the controls, the maximum decrease occurred at 50 $\mu \mathrm{M}$, showing a variation of $46.1,44.7,18.5,27.0$, 25.1 and $66.8 \%$, for root mass, shoot mass, root length, shoot length, net photosynthetic rate and chlorophyll content respectively. At this concentration, As accumulation in the shoot was much higher $\left(263.3 \mu \mathrm{g} \mathrm{As} \mathrm{g}^{-1} \mathrm{DW}\right)$ than in roots (134.6 $\mu \mathrm{g} \mathrm{As} \mathrm{g}^{-1} \mathrm{DW}$ ), indicating a tendency for metal retention preferably in the aerial plant parts (Fig. 2). The low $(5 \mu \mathrm{M})$ As treatment did not influence the root and shoot growth significantly, 
which suggests that Pusa Jai Kisan is tolerant for As at low doses. Nevertheless, higher doses (25 and $50 \mu \mathrm{M}$ ) were toxic and caused significant reductions. Khan et al. (2009) reported a significant reduction in growth parameters of this plant at $25 \mu \mathrm{M}$ As exposure. Our results also showed a substantial diminution in growth parameters at $25 \mu \mathrm{M}$ dose. Growth inhibition at higher concentrations may be linked with lower mitotic activity in the root meristematic zone or inhibition of cell enlargement in the elongation zone as a consequence of decreased cellular turgor (Mumthas et al. 2010), as root lengthening is controlled by the cell-division rate in the apical meristems and by expansion and elongation of the newly formed cells. A dose-dependent inhibition of root growth (and of the whole plant), has been demonstrated in wheat, mung bean, arabidopsis, broad bean and rice (Ansari et al. 2013). Moreover, the higher HM build-up in plant tissues may affect the energy balance within the plant because plants would use energy to survive these high metal concentrations (Greger 1999), by activating production of antioxidants and phytochelatins and this would hamper photosynthesis, leading to decline in growth (Cao et al. 2009).
Arsenic is known to inhibit biomass production in various plant species (Srivastava et al. 2005), which might be due to increased tissue permeability and tissue loss, inhibition of cell division, reduced enzyme activity and/or the Asinduced oxidative stress (Xiao et al. 2011).

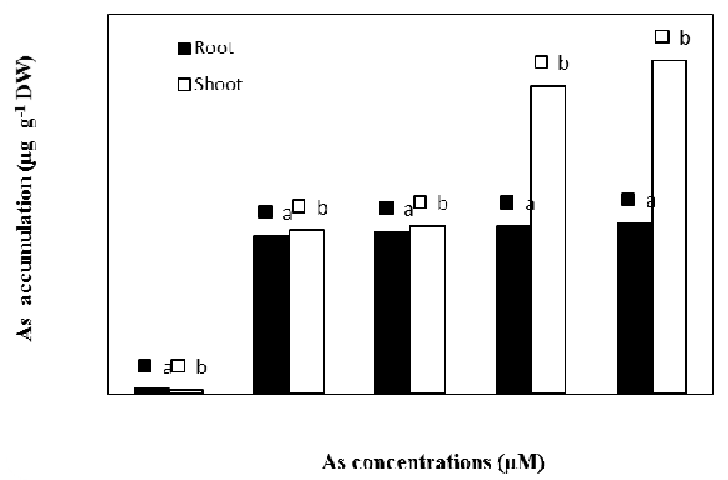

Fig. 2. As accumulation in the root and shoot of 20 day old Brassica juncea cv. Pusa Jai Kisan grown with and without As stress. All values are the mean of four independent experiments with four replications each $(n=12)$. Significant $(p$ $\leq \mathbf{0 . 0 5})$ compared to control. Error bars are not shown as they are insignificant, the percentage error in replicate reproducibility was $<2 \%$ in all cases.

Table 1. Plant growth parameters of Brassica juncea. cv Pusa Jai Kisan as influenced by as treatment, observed in 20 day old plants.

\begin{tabular}{lccccc}
\hline Parameters & \multicolumn{5}{c}{ As concentration $(\boldsymbol{\mu M})$} \\
& $\mathbf{0}$ & $\mathbf{5}$ & $\mathbf{1 0}$ & $\mathbf{2 5}$ & $\mathbf{5 0}$ \\
\hline${\text { Root dry mass }\left(\mathrm{g} \mathrm{plant}^{-1}\right)}^{0.13 \pm 0.03^{\mathrm{a}}}$ & $0.12 \pm 0.03^{\mathrm{b}}$ & $0.11 \pm 0.04^{\mathrm{c}}$ & $0.10 \pm 0.03^{\mathrm{d}}$ & $0.07 \pm 0.03^{\mathrm{e}}$ \\
Shoot dry mass $\left(\mathrm{g} \mathrm{plant}^{-1}\right)$ & $0.38 \pm 0.05^{\mathrm{a}}$ & $0.37 \pm 0.04^{\mathrm{b}}$ & $0.31 \pm 0.02^{\mathrm{c}}$ & $0.30 \pm 0.05^{\mathrm{cd}}$ & $0.21 \pm 0.06^{\mathrm{e}}$ \\
Root length $(\mathrm{cm})$ & $11.4 \pm 0.3^{\mathrm{a}}$ & $11.0 \pm 0.3^{\mathrm{b}}$ & $10.0 \pm 0.01^{\mathrm{bc}}$ & $9.4 \pm 0.3^{\mathrm{d}}$ & $9.3 \pm 0.4^{\mathrm{e}}$ \\
Shoot length $(\mathrm{cm})$ & $14.8 \pm 0.3^{\mathrm{a}}$ & $14.7 \pm 0.3^{\mathrm{b}}$ & $12.8 \pm 0.3^{\mathrm{c}}$ & $11.8 \pm 0.3^{\mathrm{d}}$ & $10.8 \pm 0.3^{\mathrm{e}}$ \\
Photosynthetic rate & $13.7 \pm 0.3^{\mathrm{a}}$ & $13.6 \pm 0.03^{\mathrm{b}}$ & $11.9 \pm 0.1^{\mathrm{c}}$ & $11.1 \pm 0.1^{\mathrm{cd}}$ & $10.3 \pm 0.06^{\mathrm{e}}$ \\
$\quad\left(\mu\right.$ mol CO $\left._{2} \mathrm{~m}^{-2} \mathrm{sec}^{-1}\right)$ & & & & & \\
Chlorophyll content $_{\quad}$ & $1.6 \pm 0.1^{\mathrm{a}}$ & $1.4 \pm 0.02^{\mathrm{b}}$ & $0.95 \pm 0.03^{\mathrm{c}}$ & $0.76 \pm 0.02^{\mathrm{d}}$ & $0.52 \pm 0.03^{\mathrm{e}}$ \\
$\quad\left(\mathrm{mg} \mathrm{g}^{-1} \mathrm{FW}\right)$ & & & &
\end{tabular}

All values are the mean of four independent experiments having four replicates in each experiment $(\mathrm{n}=12)$. Means in a row marked with similar letters do not differ significantly $(p<0.05)$ 
Photosynthetic pigments: Since photosynthetic activity is intimately correlated to the quantity of chloroplast pigment, as observed in this as well as earlier studies on different plants such as chickpea (Srivastava et al. 2014), tomato and rice seedlings (Choudhary et al. 2010), and because these pigments are among the main receptors of metal toxicity (Miteva and Merakchiyska 2002), the resultant inhibition of chlorophyll synthesis becomes the limiting factor for photosynthesis. In metal-stressed plants, $\mathrm{Mg}$ ion in the chlorophyll molecule is usually substituted with the available heavy metal under low-light conditions, which markedly disturbs the photosynthetic activity (Srivastava et al. 2014). Furthermore, the reduction in chlorophyll content in plants exposed to heavy-metal stress may be due to (a) inhibition of important enzymes, such as $\delta$-aminolevulinic acid dehydratase (ALA-dehydratase) and protochlorophyllide reductase (John et al. 2008), associated with chlorophyll biosynthesis, (b) impairment in the supply of $\mathrm{Mg}^{2+}$ and $\mathrm{Fe}^{2+}$ required for the synthesis of chlorophylls, (c) $\mathrm{Zn}^{2+}$ deficiency resulting in inhibition of enzymes such as carbonic anhydrase, and (d) replacement of $\mathrm{Mg}^{2+}$ ions associated with the tetrapyrrole ring of the chlorophyll molecule (John et al. 2008).

Arsenic accumulation: Heavy-metal accumulation in higher plants stimulates a number of intracellular changes and few of them contribute directly to the metal tolerance capability in plants (Sinha et al. 2007). In our study, greater As accumulation in shoots $\left(243.3 \mu \mathrm{g} \mathrm{As} \mathrm{g}^{-1} \mathrm{DM}\right)$ than in roots $\left(134.6 \mu \mathrm{g} \mathrm{As} \mathrm{g}^{-1} \mathrm{DM}\right)$ at $20 \mathrm{DAT}$ at higher $(50 \mu \mathrm{M})$ dose (Fig. 2) implies that a considerable amount of As was translocated to aerial plant parts (Ansari et al. 2013). Gupta et al. (2009) asserted that As accumulation was more in roots than in shoots of Indian mustard after a short-term (2d) exposure, but it was more in shoots than in roots after a longer (5d) exposure, possibly due to involvement of As transporters in the long-distance (root to shoot) metal translocation.
Lipid peroxidation levels, expressed in terms of MDA and $\mathrm{H}_{2} \mathrm{O}_{2}$ contents, increased with increase in As concentration in the medium (Fig. $3)$. The most significant increase in lipid peroxidation at the highest concentration $(50 \mu \mathrm{M})$, showing an increase of $46.2 \%$ in MDA and $63.1 \%$ in $\mathrm{H}_{2} \mathrm{O}_{2}$ contents, over the control. Generally, these increases in MDA and $\mathrm{H}_{2} \mathrm{O}_{2}$ contents were linearly correlated $\left(r^{2}>0.97\right)$ with the increase in As concentrations (Fig. 3). In addition, slopes of the curves for 2 and 5 DAT samples were generally similar within the experimental error, indicating that the relative changes in MDA and $\mathrm{H}_{2} \mathrm{O}_{2}$ contents were similar regardless of the time of analysis, with the 5 DAT results being consistently higher by a predefined amount equal to 2.3 and 1.4 $\mu \mathrm{mol} \mathrm{g}^{-1}$ FW for MDA and $\mathrm{H}_{2} \mathrm{O}_{2}$, respectively. Plant responses to metals are complex and may involve several different simultaneous defense mechanisms to withstand metal toxicity. However, heavy metals primarily damage the molecular structure in plant cells either directly or indirectly through formation of reactive oxygen species (ROS) (Iqbal et al. 2014), including free radical and non-radical molecules of high reactivity, like $\mathrm{H}_{2} \mathrm{O}_{2}$ and singlet oxygen $\left({ }^{1} \mathrm{O}_{2}\right)$. Membrane lipids are particularly susceptible to free radical attack. Protonation of the superoxide radical produces hydroperoxyl radicals $\left(-\mathrm{OH}, \mathrm{H}_{2} \mathrm{O}_{2}\right)$, which change fatty acids into toxic lipid peroxides, damaging the biological membranes (Anjum et al. 2014). Active oxygen radicals may trigger the continuous unsaturated membrane-fatty-acid peroxidation in producing the lipid-peroxidation products, like MDA (Mishra et al. 2008). Since lipid peroxidation is attributed to oxidative damage, the levels of MDA, a usual product of lipid peroxidation, can be recruited as a potential indicator of oxidative stress (Suthar et al. 2014). In our study, both the MDA contents and $\mathrm{H}_{2} \mathrm{O}_{2}$ production increased linearly with increased As concentrations (Fig. 3). Consequently, the MDA and $\mathrm{H}_{2} \mathrm{O}_{2}$ levels in treated samples were significantly greater than in the controls, this being a strong evidence of As-induced oxidative stress in 
cv. Pusa Jai Kisan. In a previous study, Khan et al. (2009) demonstrated that a short-term ( $<4$ days) As exposure of this species did not significantly affect the antioxidant metabolism. Therefore, in the current study, the exposure period was increased to 10 days to examine the longer-term exposure effect.
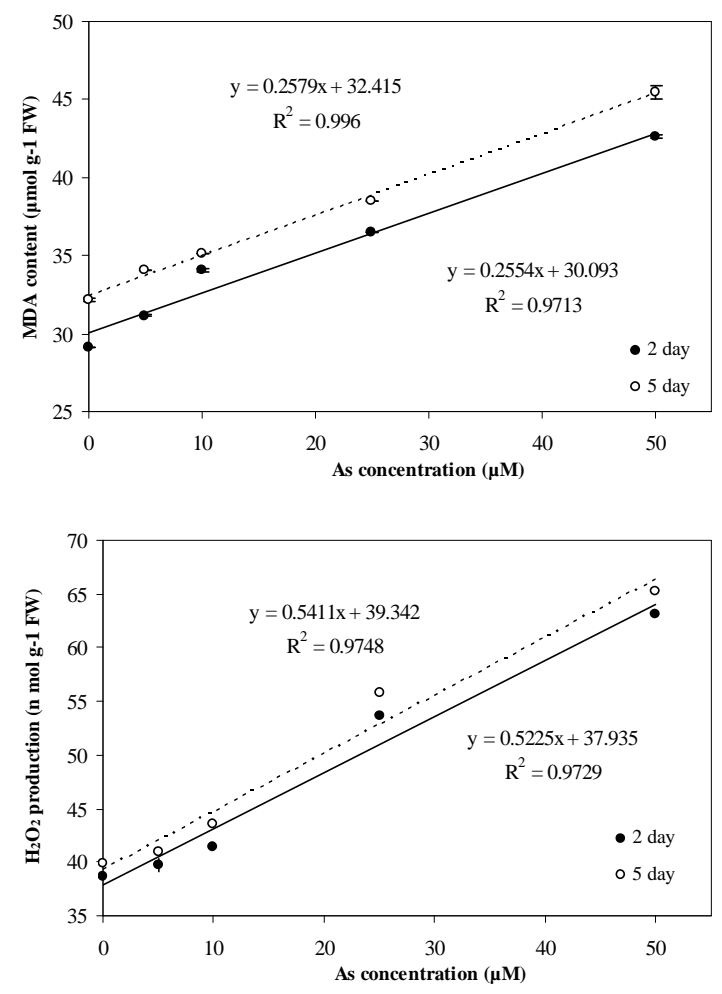

Fig. 3. MDA (a) and $\mathrm{H}_{2} \mathrm{O}_{2}$ contents (b) in the leaves of $2 \& 5$ day old Brassica juncea cv. Pusa Jai Kisan grown at various levels of As. All values are the mean of four independent experiments with four replications each $(\mathrm{n}=12)$. Significant $(\mathbf{p} \leq \mathbf{0 . 0 5})$ compared to control. Solid and dashed lines correspond to simple linear fits of the data at 2 and $5 \mathrm{~d}$, respectively. Error bars are not shown as they are insignificant, the percentage error in replicate reproducibility was $<2 \%$ in all cases.
Antioxidative enzymes: Enzyme activities of SOD, APX, CAT and GR were analysed in the leaves of Indian mustard plants subjected to different As concentrations (Fig. 4). These enzymes showed increased activity with increase in As concentration in the medium. The SOD and CAT activities increased by 65.8 and $28.5 \%$ at $2 \mathrm{~d}$ and by 49.6 and $35.5 \%$ at $5 \mathrm{~d}$, respectively, as compared with their controls. However, the APX and GR activities increased by 49.5 and $150 \%$ after 2-day treatment and by 40.1 and $187.5 \%$ after 5-day treatment, respectively (Fig. 4). These differences showed significant at $\mathrm{p} \leq 0.05$. The activities of the antioxidant enzymes were fit with good correlations $\left(\mathrm{r}^{2}>0.95\right)$ by a rise to the maximum curve (Table 2). The observed activities were consistently higher at $5 \mathrm{~d}$ exposure than at $2 \mathrm{~d}$ exposure; while the shapes of the curves at 2 and $5 \mathrm{~d}$ were similar for SOD and APX, it was not so for CAT and GR, which showed a slightly greater activity for 5-day exposure than for 2-day exposure. The SOD is one of the most vital antioxidant enzymes defending plants against the ROS-mediated toxicity by catalyzing the superoxide radical dismutation to hydrogen peroxide and molecular oxygen (Khan et al. 2009). Gupta et al. (2009) observed that As induced a strong antioxidative defense at low $(<150 \mu \mathrm{M})$ As concentration, which declined at higher $(300 \mu \mathrm{M})$ concentrations in two different cultivars of Indian mustard. In the present study, the As concentrations were much lower than those required to cause SOD inactivation and, consequently, the SOD activity was significantly greater in the leaves of $B$. juncea at both the minimum $(5 \mu \mathrm{M})$ and maximum $(50 \mu \mathrm{M})$ As doses in comparison with the controls. Since SOD activity produces $\mathrm{H}_{2} \mathrm{O}_{2}$, which again is toxic for cells and needs further detoxification by CAT in the AsA-GSH cycle, CAT is another important enzyme involved in the process to dismutate $\mathrm{H}_{2} \mathrm{O}_{2}$ 
and decompose it to $\mathrm{H}_{2} \mathrm{O}$ and $\mathrm{O}_{2}$ (Khan et al. 2009). We found that involvement of CAT was insignificant in active $\mathrm{H}_{2} \mathrm{O}_{2}$ reduction regardless of the dose of As. Similar results for CAT activity were observed previously under other abiotic stresses, which could be because of inhibited enzyme synthesis or a changed assembly of enzyme subunits, as suggested by Ogawa et al.
(1997). The AsA-GSH cycle in chloroplasts mainly involves APX and GR enzymes. In our experiment, APX activity was significantly enhanced with increase in the As dose and the duration of exposure. The enhanced APX activity provides a clue of the role of APX in the dismutation of $\mathrm{H}_{2} \mathrm{O}_{2}$ and its up-regulation in As-induced oxidative stress.
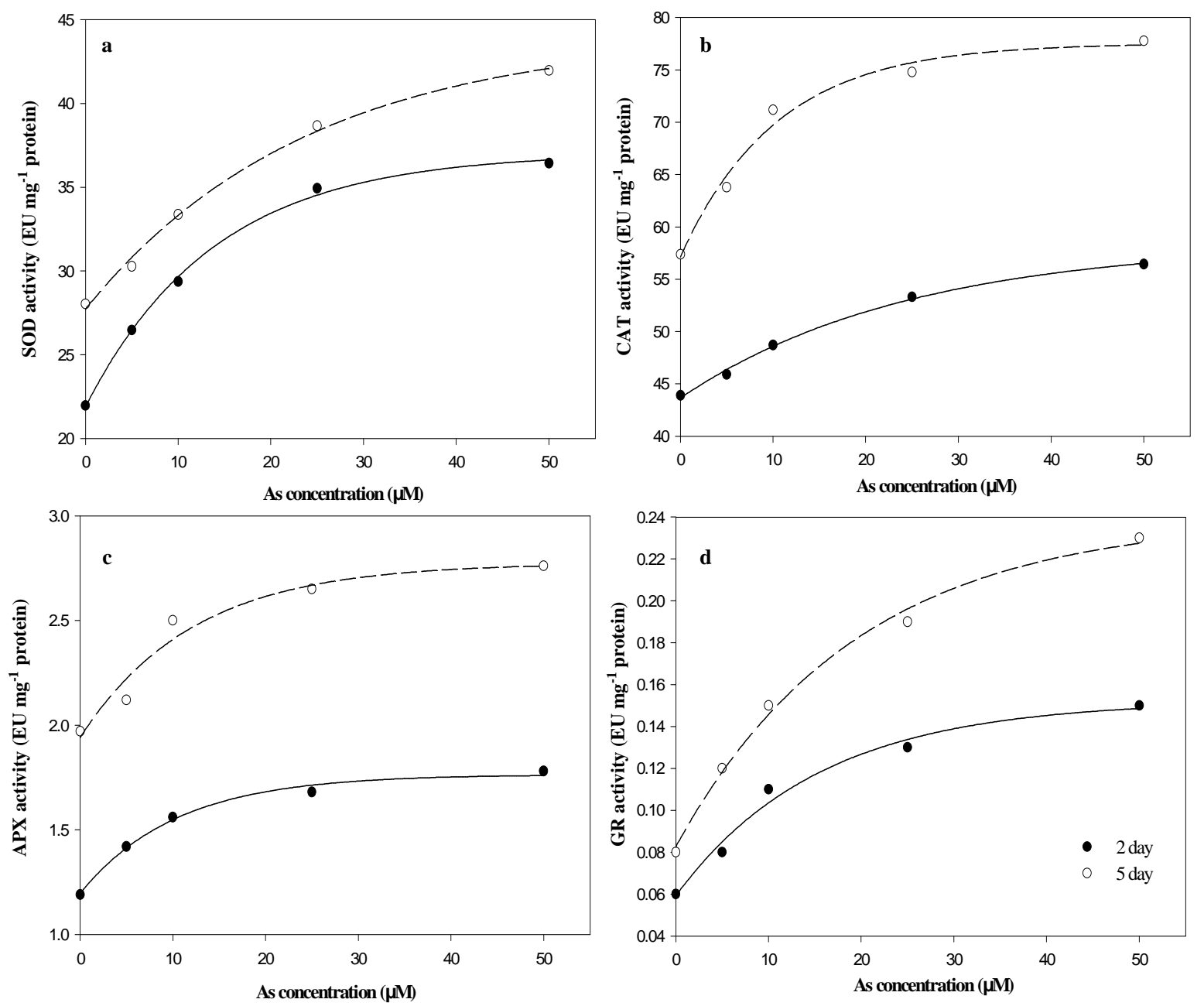

Fig. 4. Activities of SOD (a), CAT (b), APX (c) and GR (d) in 2 and 5 day old Brassica juncea cv. Pusa Jai Kisan grown with and without As stress. All values are the mean of four independent experiments with four replications each $(n=12)$. Significant $(p \leq 0.05)$ compared to control. 
Table 2. Best fit parameters for enzyme activities of SOD, CAT, APX and GR at 2 and 5 d due to stress induced by increased as concentration.

\begin{tabular}{lcccc}
\hline Enzyme Monitored & \multicolumn{4}{c}{ Best Fit Parameters } \\
& $\mathbf{A}_{\mathbf{0}}$ & $\mathbf{\Delta A}$ & $\mathbf{B}$ & $\mathbf{r}^{\mathbf{2}}$ \\
\hline SOD - 2 day & $21.9 \pm 0.3$ & $15.2 \pm 0.5$ & $0.072 \pm 0.006$ & 0.998 \\
SOD - 5 day & $27.7 \pm 0.4$ & $16.4 \pm 1.1$ & $0.042 \pm 0.007$ & 0.996 \\
CAT - 2 day & $43.6 \pm 0.3$ & $14.8 \pm 0.9$ & $0.041 \pm 0.006$ & 0.997 \\
CAT - 5 day & $57.1 \pm 1.4$ & $20.4 \pm 1.8$ & $0.09 \pm 0.02$ & 0.984 \\
APX - 2 day & $1.20 \pm 0.02$ & $0.57 \pm 0.03$ & $0.10 \pm 0.01$ & 0.992 \\
APX - 5 day & $1.94 \pm 0.09$ & $0.8 \pm 0.1$ & $0.08 \pm 0.03$ & 0.957 \\
GR - 2 day & $0.059 \pm 0.006$ & $0.093 \pm 0.009$ & $0.06 \pm 0.01$ & 0.984 \\
GR - 5 day & $0.083 \pm 0.005$ & $0.16 \pm 0.01$ & $0.052 \pm 0.009$ & 0.995 \\
\hline
\end{tabular}

Significant increases $(\mathrm{p} \leq 0.05)$ were recorded in AsA contents of the leaves of As-treated plants till $5 \mathrm{~d}$ of metal exposure and a comparatively steady level thereafter (Fig. 5a). In comparison with the control, there was a sharp enhancement of $19.6 \%$ and $41.0 \%$ in the AsA contents with the low and high As treatments, respectively. Accumulation of GSH in the leaves of As-exposed plants was recorded from $2 \mathrm{~d}$ of exposure onwards and was significant $(\mathrm{p} \leq 0.05)$ relative to the control (Fig. 5b). The level of ascorbate (AsA), a major reducing substrate for $\mathrm{H}_{2} \mathrm{O}_{2}$ detoxification (Anjum et al. 2008), significantly increased with As treatments, as compared with the controls. DHA is formed as a result of reduction of AsA and is recycled back to AsA, using the GSH as an electron donor. GR is a key enzyme involved in the reduction of GSSG to GSH through oxidation of NAD $(\mathrm{P}) \mathrm{H}$ to NAD $(\mathrm{P})^{+}$. Since the oxidized glutathione (GSSG) is converted back to GSH with the help of GR, the GSH witnesses a concentration as well as time-dependent enhancement in the Asexposed plants. Accordingly, an increased GSH concentration corresponds with the capacity of plants to combat the oxidative stress caused by metals. In a recent study, Indian mustard plants exposed to $0.0,0.1,0.2$ and $0.3 \mathrm{mM}$ concentration of arsenic (V) and harvested after 30 and 60 days of sowing showed
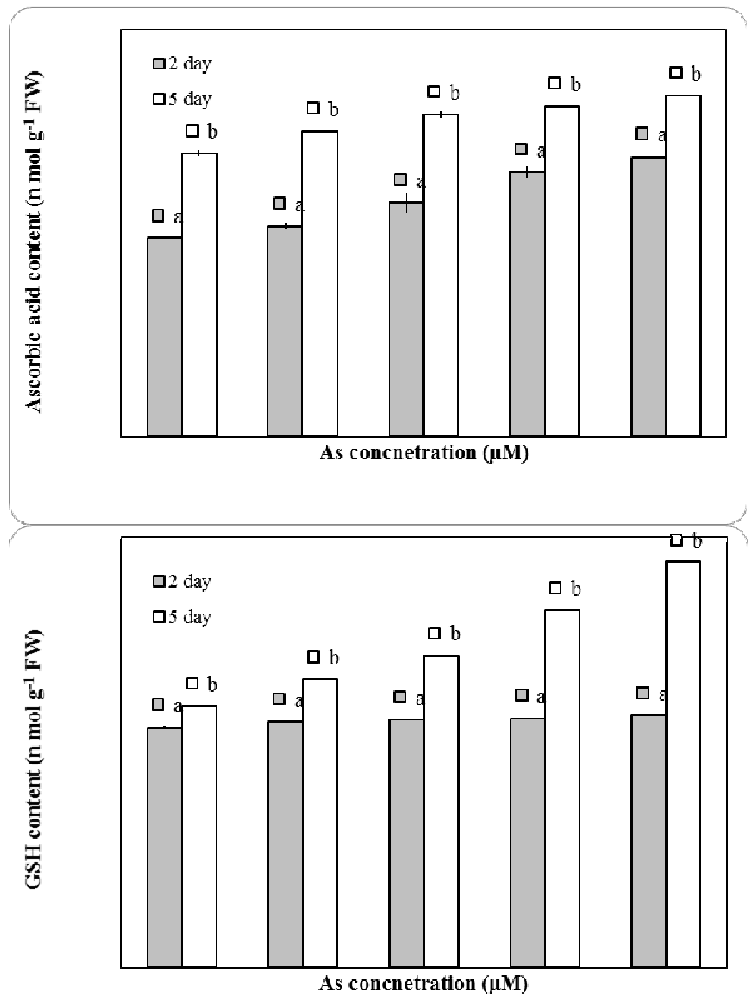

Fig. 5. Contents of AsA (a) and GSH (b) in leaves of $2 \& 5$ day old Brassica juncea cv. Pusa Jai Kisan grown with and without As stress. All values are the mean of four independent experiments with four replications each $(n=12)$. Error bars are one standard deviation of the mean. Significant $(p \leq 0.05)$ compared to control.

ECOPRINT VOL 22, 2015 
that As significantly hampered the growth variables, triggered the modulations of various stress markers like proteins, antioxidant enzymes, and MDA content, and induced the synthesis of four brassinosteroids, namely castasterone, teasterone, 24-epibrassinolide, and typhasterol (Kanwar et al. 2015). In the present study, GR activity showed a considerable increase under the influence of As treatments, being the maximum with the highest As doses, indicating that, on the whole, the AsA-GSH cycle in Brassica juncea was quite capable of detoxifying the reactive oxygen species.

\section{CONCLUSIONS}

As treatments induced oxidative stress, as demonstrated by enhanced lipid peroxidation and $\mathrm{H}_{2} \mathrm{O}_{2}$ levels cv. Pusa Jai Kisan of Indian mustard. However, to withstand the As toxicity, it developed a defence strategy through modulation of enzymatic and non-enzymatic antioxidant components to prevent the expected cellular damage. This could successfully nullify the deleterious effects and helped in maintaining plant growth at low As concentration. In conclusion, Pusa Jai Kisan is a suitable As phytoremediator due to its high As-accumulation capacity and a sound antioxidant defense system. The As content in treated plants increased linearly with increase in the As levels applied, with As accumulation being higher in shoots than in roots.

\section{ACKNOWLEDGEMENTS}

The first author thanks the Hamdard National Foundation, New Delhi, for financial assistance for this study. Mohd Kafeel Ahamd Ansari was a Visiting Scientist at the University of South Australia during the development of this manuscript. Last co-author gratefully acknowledges the financial support of the Australian Research Council Future Fellowship Scheme (grant number: FT120100799) for funding his salary.

\section{REFERENCES}

Aebi, H.E. 1984. Catalase in vitro. Methods Enzymol. 105:121-126.

Anjum, N.A., A. Sofo, A. Scopam, A. Roychoudhury, S.S. Gill, M. Iqbal, A.S. Lukatkin, E. Pereira, A.C., Duarte and I. Ahmad. 2015. Lipids and proteins-major targets of oxidative modifications in abiotic stressed plants. Environ. Sci. Pollu. Resi. 22(6):4099-121.

Ansari, M.K.A., A. Ahmad, S. Umar and M. Iqbal. 2009. Mercury-induced changes in growth variables and antioxidative enzymes in Indian mustard (Brassica juncea L.). J. Plant Interaction 4:131-136.

Ansari, M.K.A., A. Ahmad, S. Umar, M.H. Zia, M. Iqbal and G. Owens. 2015. Genotypic variation in phytoremediation potential of Indian mustard exposed to nickel stress: A hydroponic study. Inter. J. Phyto. 17(2):135144.

Ansari, M.K.A., S. Umar, A. Ahmad, H.S. Shahid, M. Iqbal, G. Owens and S. Hong-Bo. 2013. Screening Indian mustard genotypes for phytoremediating arsenic-contaminated soils. Clean-Soil Air Water 2(41):195-201.

Bergmeyer, H.U., K. Gawehn and M. Grassi. 1974. Enzymes as biochemical reagents. In: Methods in Enzymatic Analysis. (ed.) Bergmeyer, H.U. Academic Press, New York, pp. 425-522.

Bradford, M.M. 1976. A rapid and sensitive method for the quantitation of microgram quantities of protein utilizing the principle of protein-dye binding. Annual Biochem. 72:248-254.

Cao, H., Y. Jiang, J. Chen, H. Zhang, W. Huang, L. Li and W. Zhang. 2009. Arsenic accumulation in Scutellaria baicalensis georgi and its effects on plant growth and pharmaceutical components. J. Hazard. Mat. 171:508-513. 
Chaney, R.L. 1983. Plant uptake of inorganic waste constitutes. In: Land Treatment of Hazardous Wastes. (eds.) Parr, J.F., P.B. Marsh and J.M. Kla. Noyes Data Corp. Park Ridge, pp. 50-76.

Choudhary, B., S. Chowdhury and A.K. Biswas. 2010. Regulation of growth and metabolism in rice (Oryza sativa L.) by arsenic and its possible reversal by phosphate. J. Plant Interaction 1(6): 15-24.

Dhindsa, R.H., P. Plumb-Dhindsa and T.A. Thorpe. 1981. Leaf senescence correlated with increased level of membrane permeability, lipid peroxidation and decreased level of SOD and CAT. J. Exp. Bot. 32:93-101.

Foyer, C.H. and B. Halliwell. 1976. The presence of glutathione and glutathione reductase in chloroplasts: A proposed role in ascorbic acid metabolism. Planta 133:21-25.

Gupta, M., P. Sharma, N.B. Sarin, A.K. Sinha. 2009. Differential response of arsenic stress in two varieties of Brassica juncea $\mathrm{L}$. Chemosphere 74:1201-1208.

Heath, R.L. and L. Packer. 1968. Photoperoxidation in isolated chloroplasts. I. Kinetics and stoichiometry of fatty acid peroxidation. Arch. Biochem. Biophys. 125:189-190.

Hiscox, J.H. and G.F. Israelstam. 1979. A method for extraction of chlorophyll from leaf tissues without maceration. Canad. J. Bot. 57:13321334.

Hodges, D.M., C.J. Andrews, D.A. Johnson and R.I. Hamilton. 1996. Antioxidant compound responses to chilling stress in different sensitive inbred maize lines. Physiologia Plantarum 98:685-692.

Iqbal, M., A. Ahmad, M.I. Qureshi, M.K.A. Ansari, I.M. Aref, P.R. Khan, S.S. Hegazy, H. El-Atta, A. Husen and K.R. Hakeem. 2015.
Improving phytoextraction capacity of plants to scavenge metal (loid)-contaminated sites. Environ. Rev. 23:1-22.

John, R., P. Ahmad, K. Gadgil and S. Sharma. 2008. Effect of cadmium and lead on growth, biochemical parameters and uptake in Lemna polyrrhiza L. Plant Soil Environ. 54(6):262270.

Kanwar, M.K., K. Poonam and R. Bhardwaj. 2015. Arsenic-induced modulation of antioxidative defense system and brassinosteroids in Brassica juncea L. Eco. Environ. Saf. 115:119-125.

Khan, I., A. Ahmad and M. Iqbal. 2009. Modulation of antioxidant defence system for arsenic detoxification in Indian mustard. Eco. Environ. Saf. 72:626-634.

Lamhamdi, M., A. Bakrim, A. Aarab, R. Lafont, F. Sayah. 2011. Lead phytotoxicity on wheat (Triticum aestivum L.) seed germination and seedlings growth. Comptes Rendus Biologies 334:118-126.

Mishra, S., S. Srivastava, R.D. Tripathi and P.K. Trivedi. 2008. Thiol-metabolism and antioxidant systems complement each other during arsenate detoxification in Ceratophyllum demersum L. Aquat Toxico. 86:205-215.

Mumthas, S., A.A. Chidambaram, P. Sundaramoorthy and K.S. Ganesh. 2010. Effect of arsenic and manganese on root growth and cell division in root tip cells of green gram (Vigna radiata L.). J. Food Agri. 22(4):285-297.

Nakano, Y. and K. Asada. 1984. Hydrogen peroxide is scavenged by ascorbate-specific peroxidase in spinach chloroplasts. Plant Cell Physiol. 22:867-880.

Ogawa, K., S. Kanematsu and K. Asada. 1997. Generation of superoxide anion and 
localization of $\mathrm{Cu}-\mathrm{Zn}$ superoxide dismutase in the vascular tissue of spinach hypocotyls and their association with lignification. Plant Cell Physiol. 38:1118-1126.

Okuda, T., Y. Matsuda, A. Yamanaka and S. Sagisaka. 1991. Abrupt increase in the level of hydrogen peroxide in leaves of winter wheat is caused by cold treatment. Plant Physiol. 97:1265-1267.

Sinha, S., A.K. Gupta and K. Bhatt. 2007. Uptake and translocation of metals in fenugreek grown on soil amended with tannery sludge: involvement of antioxidants. Eco. Environ. Saf. 67:267-277.

Srivastava, S. and Y.K. Sharma. 2014. Arsenic induced changes in growth and metabolism of black gram seedlings (Vigna Mungo L.) and the role of phosphate as an ameliorating agent environ. Processed 1:431-445.

Suthar, B., J. Pansuriya, M.M. Kher, V.R. Patel and M. Nataraj. 2014. Biochemical changes under chromium stress on germinating seedlings of Vigna radiate. Notulae Scientia Biologicae 6(1):77-81.

Xiao, R., J.H. Bai, Q.H. Wang, L.B. Huang and X.H. Liu. 2011. Assessment of heavy metal contamination of wetland soils from a typical aquatic-terrestrial ecotone in haihe river basin, north China. Clean - Soil, Air, Water 39(7):612-618. 